\title{
Pharmacological Management of Painful Peripheral Neuropathies: A Systematic Review
}

\author{
Andreas Liampas · Martina Rekatsina $\cdot$ Athina Vadalouca · \\ Antonella Paladini · Giustino Varrassi · Panagiotis Zis
}

Received: August 6, 2020 / Accepted: October 8, 2020 / Published online: November 3, 2020

(c) The Author(s) 2020

\begin{abstract}
Introduction: Peripheral neuropathic pain (PNP) arises either acutely or in the chronic phase of a lesion or disease of the peripheral nervous system and is associated with a notable disease burden. The management of PNP is often challenging. The aim of this systematic review was to evaluate current evidence, derived from randomized controlled trials (RCTs) that have assessed pharmacological
\end{abstract}

Electronic supplementary material The online version of this article (https://doi.org/10.1007/s40122$020-00210-3)$ contains supplementary material, which is available to authorized users.

A. Liampas · P. Zis ( ()

Medical School, University of Cyprus, Nicosia, Cyprus

e-mail: takiszis@gmail.com

\section{Rekatsina}

Whipps Cross Hospital, Barts Health NHS Trust, London, UK

A. Vadalouca

Pain and Palliative Care Center, Athens Medical

Center, Athens, Greece

\section{A. Paladini}

Department of Life, Health and Environmental Sciences (MESVA), University of L'Aquila, L'Aquila, Italy

G. Varrassi

Paolo Procacci Foundation, Rome, Italy interventions for the treatment of PNP due to polyneuropathy $(\mathrm{PN})$.

Methods: A systematic search of the PubMed database led to the identification of 538 papers, of which 457 were excluded due to not meeting the eligibility criteria, and two articles were identified through screening of the reference lists of the 81 eligible studies. Ultimately, 83 papers were included in this systematic review. Results: The best available evidence for the management of painful diabetic polyneuropathy (DPN) is for amitriptyline, duloxetine, gabapentin, pregabalin and venlafaxine as monotherapies and oxycodone as add-on therapy (level II of evidence). Tramadol appears to be effective when used as a monotherapy and add-on therapy in patients with PN of various etiologies (level II of evidence). Weaker evidence (level III) is available on the effectiveness of several other agents discussed in this review for the management of PNP due to PN.

Discussion: Response to treatment may be affected by the underlying pathophysiological mechanisms that are involved in the pathogenesis of the PN and, therefore, it is very important to thoroughly investigate patients presenting with PNP to determine the causes of this neuropathy. Future RCTs should be conducted to shed more light on the use of pharmacological approaches in patients with other forms of PNP and to design specific treatment algorithms. 
Keywords: Management; Peripheral neuropathic pain; Pharmacological; Polyneuropathy

\section{Key Summary Points}

There is a plethora of pharmacological interventions available for the management of peripheral neuropathic pain.

Amitriptyline, duloxetine, gabapentin, pregabalin and venlafaxine as monotherapies and oxycodone as add-on therapy are effective in reducing the overall pain intensity in patients with diabetic polyneuropathy (PN) (level II evidence).

Tramadol appears to be effective when used as a monotherapy and add-on therapy in patients with PN of various etiologies (level II of evidence).

Response to treatment may be affected by the underlying pathophysiological mechanisms that are involved in the pathogenesis of the neuropathy.

\section{DIGITAL FEATURES}

This article is published with digital features, including a summary slide, to facilitate understanding of the article. To view digital features for this article go to https://doi.org/10.6084/ m9.figshare.13055918.

\section{INTRODUCTION}

The term peripheral neuropathy refers to disorders of the peripheral nervous system and includes mononeuropathies, such as carpal tunnel syndrome, and polyneuropathy (PN), which can be symmetrical or asymmetrical [1]. Many aetiological factors have been implicated in the development of PN, with the most common being diabetes mellitus, cancer, drug toxicity, vitamin deficiencies, excessive alcohol consumption, increased oxidative stress, gluten sensitivity and genetics [2-9].

Peripheral neuropathic pain (PNP) is very prevalent, affecting up to two-thirds of patients with $\mathrm{PN}$, independently of the aetiology [10-12]. It is one of the most-if not the mostburdensome of neuropathic symptoms, leading to an overall poor quality of life, regardless of disease severity $[13,14]$. PNP is challenging to control, and often patients require various combinations of medications, with or without adjuvant non-pharmacological interventions, to achieve satisfactory pain management $[15,16]$.

The aim of this systematic review was to evaluate currently available evidence, derived from randomized controlled trials (RCTs) about pharmacological interventions for the treatment of PNP due to PN.

\section{METHODS}

\section{Protocol Registration}

This review was registered in PROSPERO, an international prospective register of systematic reviews, under registration number CRD42020179750.

\section{Literature Search Strategy}

A systematic literature search of the PubMed database was performed on 12 April 2020 using three medical subject heading $(\mathrm{MeSH})$ terms. Term A was "pain" OR "painful"; term B was "neuropathy" OR "polyneuropathy"; term C was "randomised" OR "randomized". The filter "clinical trial" was applied. We also searched at https://www.clinicaltrials.gov/, a resource provided by the U.S. National Library of Medicine for unpublished trials, using the same MeSH terms as above, but applying the filters "with results" AND "completed". The reference lists of articles that met the eligibility criteria were further screened to identify additional studies that may fall within the scope of this review. 


\section{Inclusion and Exclusion Criteria and Screening process}

Studies eligible to be included in this review had to meet the following inclusion criteria: (1) human subjects were involved; (2) the full article was written in English; (3) the trials were pharacological RCTs; (4) the studies were of adequate methodological quality (as described below).

The exclusion criteria were: (1) article made no reference to $\mathrm{PN}$; (2) article was not an original study (i.e. review articles, letters, medical hypotheses, etc.); (3) pain relief was not the primary aim of the study; (4) trials with less than ten patients per treatment arm; (5) withdrawal trials; (6) duplicate articles or papers from the same research teams describing the same patient population; (7) non-pharmacological trials.

All article abstracts were screened three times in a blinded fashion. Those found to meet any of the exclusion criteria were removed and any differences of opinion were discussed in a faceto-face meeting during which the abstracts were re-reviewed. All papers deemed eligible were screened again as a full article by at least three reviewers, and conflicts were settled as previously noted.

\section{Quality Assessment of Included Studies}

All studies were initially screened for bias using the Jadad scoring system [17]. Trials with Jadad score $<4$ were excluded. Studies with a Jadad score $\geq 4$ were further assessed using the Cochrane Collaboration risk of bias assessment tool [18]. See Electronic Supplementary Material for more detailed information.

\section{Data Collection Process}

Following identification of the eligible papers, all relevant data were extracted from each study in a structured coding scheme using Microsoft Excel (Microsoft Corp., Redmond, WA, USA). The information collected included population size, gender and age distribution, the type of $\mathrm{PN}$, the means used to diagnose PNP, treatment strategies, the duration of the RCT, patient response to treatment, the manner used to assess the effectiveness of the treatment, the side effects associated with the treatment and the follow-up period of the patients, where applicable. When there was uncertainty regarding how the data should be interpreted or utilized, at least three authors discussed the study in question to reach consensus.

\section{Data Synthesis}

This study used aggregate data where possible, in accordance with the Preferred Reporting Items for Systematic Reviews and Meta-Analysis (PRISMA) guidelines [19].

\section{Clinical Recommendations}

To determine the grading of evidence we used the classification proposed by the American Society of Interventional Pain Physicians (ASIPP), where applicable [20].

\section{Compliance with Ethics Guidelines}

This article is based on previously conducted studies and does not contain any studies with human participants performed by any of the authors. Therefore, ethics review was not required.

\section{RESULTS}

\section{Study Characteristics}

Our search strategy identified a total of 538 articles, of which 457 articles were excluded during the eligibility assessment. Two papers were identified through screening of the reference lists of the included papers. Ultimately, a total of 83 studies, published between 1997 and 2019, were included in the present review [21-103]. The selection process is shown in Fig. 1 (PRISMA chart). 


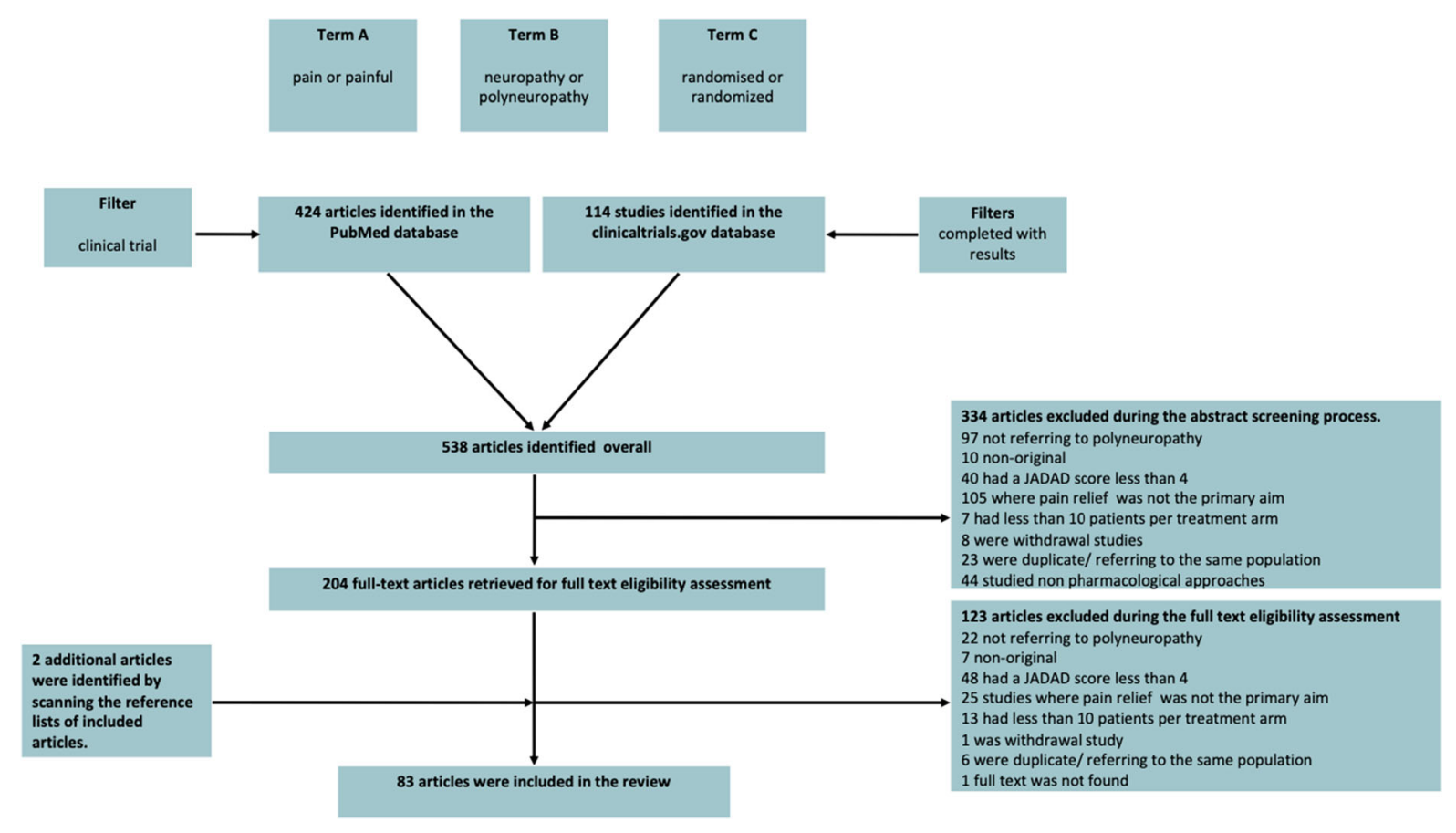

Fig. 1 PRISMA (Preferred Reporting Items for Systematic Reviews and Meta-Analysis) flow diagram

\section{Anticonvulsants}

Compared to placebo, gabapentin monotherapy has been found to be effective and well-tolerated for the management of pain and sleep interference in patients with diabetic PN (DPN) $(n=165)$ [21] and human immunodeficiency virus (HIV)-related PN (HIVPN) $(n=26)$ [22]. However, Rao et al. showed a lack of benefit when gabapentin was used as a monotherapy to treat painful chemotherapy-induced peripheral neuropathy (CIPN) [23]. The prodrug of gabapentin, gabapentin enacarbil, was not effective in treating painful DPN in 420 subjects [24]. In a double-blind, cross-over RCT, Morello et al. compared gabapentin to amitriptyline, both as monotherapies, in 25 subjects with painful DPN [25] and found that both were equally effective in managing the pain. Gilron et al. showed that a combination of gabapentin and nortriptyline is significantly more effective in pain management than gabapentin or nortriptyline alone [26]. In a double-blind placebo-controlled RCT, Sandercock et al. reported that adjuvant prolonged-released gabapentin was significantly more effective than placebo in the management of pain in subjects $(n=147)$ with painful DPN [27].

Pregabalin is the most tested drug for the management of painful PN as a monotherapy. The beneficial effect of pregabalin used to treat painful DPN has been demonstrated at higher doses of 300-600 mg daily [28-32]. However, other studies have shown that when pregabalin was used to treat painful DPN at moderate doses of $150-300 \mathrm{mg}$ daily, pain reduction at the endpoint did not differ significantly between the pregabalin and placebo groups [33-35]. Improvements in secondary outcomes, however, such as sleep, may suggest a utility of pregabalin in the overall management of DPN. In a double-blind, cross-over RCT of the painrelieving effect of pregabalin and amitriptyline in patients with painful DPN $(n=51)$, but with no signs of depression, Bansal et al. reported that both agents tested as monotherapies were safe and effective [36], with fewer side effects observed with pregabalin. Holbech et al. demonstrated that pregabalin was superior to placebo in subjects with PNP [37]. In 2013, Tesfaye et al. investigated the efficacy of pregabalin $300 \mathrm{mg}$ and duloxetine $60 \mathrm{mg}$ as 
monotherapies or in combination in 804 patients with DPN [38]. Although the combination therapy did not reach a significant level of efficacy compared to the respective monotherapies, the combination therapy was considered to be effective, safe and well tolerated. In 2016, González-Duarte et al. demonstrated the potential role of pregabalin as a monotherapy for the treatment of prediabetic small-fibre neuropathic pain in 45 subjects when compared to placebo [39].

Apart from the studies with diabetic or prediabetic subjects, pregabalin has been tested in patients with painful HIVPN as a monotherapy $(n=377)$ [40] or as an add-on $(n=302)$ [41]; however, it was not superior to placebo in this study.

In a double-blind placebo-controlled RCT $(n=323)$, Raskin et al. demonstrated that topiramate monotherapy provided pain relief more effectively than placebo in patients with moderate to severe painful DPN [42]. However, this finding was not confirmed in a larger study conducted by Thienel et al. [43].

Lacosamide is a safe and well-tolerated agent which has been demonstrated to be effective in managing pain due to DPN either as a monotherapy $[44,45])$ or as an add-on [46]. De Greef et al. showed that it is also effective in the management of pain in pure small-fibre neuropathy when used as an add-on analgesic [47].

In the initial trials Lamotrigine, as monotherapy, has initially shown a potential for the management of painful DPN [48, 49]. However, its beneficial effect was not confirmed in two larger double-blind placebo-controlled RCTs when used as an add-on for managing painful DPN [50] or when used as a monotherapy for treating painful CIPN [51]. When used as an add-on treatment lamotrigine was effective for the management of painful HIVPN [52].

Evidence on the use of sodium valproate in the management of PNP is also conflicting. Two studies reported that this drug has a potential for managing pain in subjects with painful DPN, compared to placebo, either as monotherapy [53] or in combination with glyceryl-trinitrate spray [54]. However, these results were not confirmed in another study [55].

In 2006, Beydoun et al. showed that, compared to placebo, oxcarbazepine improves pain scores when given as monotherapy in patients with painful DPN, but the benefit was not statistically significant compared to placebo [56].

Levetiracetam [57], perampanel [58] and some experimental anticonvulsants, namely ABT-639 [59] and PF-05089771 [60], have been found to be of no value for the treatment of PNP.

\section{Antidepressants}

Serotonin-Norepinephrine Reuptake Inhibitors In their RCT, Rowbotham et al. showed that venlafaxine at high doses (150-225 mg daily) was effective in treating painful DPN when compared to low-dose venlafaxine (75 mg daily) and placebo [61]. In other studies comparing venlafaxine to other antineuralgics, venlafaxine monotherapy was found to be superior to carbamazepine [62], equally effective to imipramine [63] and inferior to pregabalin [64] for the treatment of PNP.

Duloxetine is a safe and well-tolerated agent that has been used effectively to treat pain in DPN, in comparison to placebo, when used as a monotherapy [65-67] and painful CIPN, when used as an add-on treatment [68]. Compared to other antineuralgics, duloxetine monotherapy is equally effective to gabapentin for the treatment of pain due to DPN but shows better tolerability [69]. Similarly, duloxetine is equally effective to pregabalin for the treatment of pain due to DPN [38, 70].

\section{Tricyclic and Tetracyclic Antidepressants}

Tricyclic (TCAs) and tetracyclic antidepressants (TeCAs) have been tested in a few studies, but evidence for their effectiveness is somewhat contradictory. In a double-blind crossover placebo-controlled RCT, Vrethem et al. showed that amitriptyline and maprotiline, when used as monotherapies, are superior to placebo for pain management in patients with diabetic and nondiabetic PN [71]. Results from small RCTs show that amitriptyline $[25,36]$ and nortriptyline [26] are effective in the management of painful DPN. However, when administered in subjects with HIVPN neither amitriptyline nor mexiletine monotherapy provided statistically significant improvement in pain relief compared to placebo $[72,73]$. 
In 2015, Holbech et al. demonstrated the superiority of imipramine as a monotherapy or in combination with pregabalin, in comparison to pregabalin alone or placebo, in subjects with PNP [37].

\section{Selective Serotonin Reuptake Inhibitors}

Escitalopram as monotherapy appears to produce a weak to moderate pain relief compared to placebo in depressive and non-depressive patients with painful $\mathrm{PN}$ of various etiologies [74].

\section{Opioids}

A few double-blind placebo-controlled RCTs have reported that tramadol is effective in the management of PNP, either as monotherapy [75] or in a combination with paracetamol [76] or acetaminophen [77], with few and transient side effects.

Controlled-release oxycodone has been shown to improve moderate to severe pain due to DPN, compared to placebo, when used as an add-on treatment [78, 79]. However, in a double-blind placebo-controlled phase II RCT, the beneficial effect of oxycodone/naloxone when used as adjuvant to pregabalin in opioid-naïve patients suffering from PNP was not confirmed [80].

In a double-blind placebo-controlled RCT, Shaibani et al. demonstrated that dextromethorphan/quinidine, when used as a monotherapy, provides a significant reduction in pain due to DPN. At high doses, however, there is a risk for serious adverse effects, such as hypertensive crises and cardiac arrhythmias [81].

In 2015, the effectiveness of adjuvant use of cebranopadol compared to placebo and pregabalin was tested in a double-blind RCT in subjects with DPN; the authors found that this opioid was statistically effective in pain relief when administered at a dose of $600 \mu \mathrm{g}$ daily [82].

\section{Cannabinoids}

Adjuvant treatment with delta-9-tetrahydrocannabinol has shown a potential for the management of painful HIVPN, but current evidence is based only on small placebo-controlled studies [83, 84].

\section{Topical Treatments}

Capsaicin has been used either as a patch or a lotion in different concentrations. Studies have demonstrated that the application of a capsaicin $8 \%$ patch is effective in the management of pain due to HIVPN [85] and DPN [86]. Howevr, other studies on capsaicin lotion did not achieve a statistically significant pain reduction in subjects with pain due to DPN $[87,88]$.

Ketamine/amitriptyline cream has been found to be of no therapeutic value compared to placebo for alleviating painful DPN [89] or CIPN [90].

The application of glyceryl-trinitrate spray [91] and isosorbide dinitrate spray [92] has been reported to provide a statistically significant, but short-lasting, analgesic effect and improvement in burning sensation, when used in patients with painful DPN.

Topical clonidine as add-on, although safe, did not reach statistical significance for the management of painful DPN [93].

\section{Monoclonal Antibodies}

In a double-blind placebo-controlled RCT on the pain-relieving effect of tanezumab as a monotherapy in patients with painful DPN, Bramson et al. showed that tanezumab achieved a statistically significant reduction of pain, with mild and transient side effects but not any change in the sensory function of small and large fibres [94].

\section{Botulinum Toxin Type A}

In a small double-blind, cross-over placebocontrolled RCT, Yuan et al. investigated the efficacy of intradermal botulinum toxin type $A$ injections at the dorsum of the foot as add-on for the management of PNP due to diabetes, and reported a significant reduction in pain intensity [95]. 
Table 1 List of drugs and their respective effectiveness on the management of pain due to polyneuropathy

\begin{tabular}{|c|c|c|c|}
\hline Drug & Monotherapy or add-on & Type of polyneuropathy & Effectiveness ${ }^{a}$ \\
\hline \multirow[t]{2}{*}{ Amitriptyline } & Monotherapy & DPN & Effective (level II) \\
\hline & Monotherapy & HIVPN & Ineffective \\
\hline Acetyl L-carnitine (ALCAR) & Unclear & HIVPN & Ineffective \\
\hline Botulinum toxin type $\mathrm{A}$ & Add-on & DPN & effective (level III) \\
\hline \multirow[t]{2}{*}{ Capsaicin $8 \%$ patch } & Add-on & DPN & Effective (level III) \\
\hline & Add-on & HIVPN & Effective (level III) \\
\hline Capsaicin $0.075 \%$ lotion & Add-on & DPN & Ineffective \\
\hline Capsaicin $0.025 \%$ gel & Add-on & DPN & Ineffective \\
\hline Cebranopadol & Add-on & DPN & Effective (level III) \\
\hline Citrullus colocynthis (topical application) & Unclear & $\mathrm{DPN}$ & Effective (level III) \\
\hline Clonidine (topical application) & Add-on & DPN & Ineffective \\
\hline Delta-9-tetrahydrocannabinol & Add-on & HIVPN & effective (level III) \\
\hline Dextromethorphan/quinidine & Monotherapy & DPN & Effective (level III) \\
\hline \multirow[t]{2}{*}{ Duloxetine } & Monotherapy & DPN & Effective (level II) \\
\hline & Add-on & CIPN & Effective (level III) \\
\hline Escitalopram & Monotherapy & Various etiologies & Effective (level III) \\
\hline \multirow[t]{3}{*}{ Gabapentin } & Monotherapy & DPN & Effective (level II) \\
\hline & Monotherapy & HIVPN & Effective (level III) \\
\hline & Monotherapy & CIPN & Ineffective \\
\hline Glyceryl trinitrate spray & Unclear & DPN & Effective \\
\hline Imipramine & Monotherapy & Various etiologies & Effective (level III) \\
\hline Isosorbide dinitrate spray & Monotherapy & DPN & Effective (level III) \\
\hline \multirow[t]{2}{*}{ Ketamine/amitriptyline cream } & Unclear & DPN & Ineffective \\
\hline & Add-on & CIPN & Ineffective \\
\hline \multirow[t]{2}{*}{ Lacosamide } & Monotherapy or add on & DPN & Effective (level III) \\
\hline & Add-on & SFN & Effective (level III) \\
\hline \multirow[t]{3}{*}{ Lamotrigine } & Monotherapy & CIPN & Ineffective \\
\hline & Monotherapy or add on & DPN & Contradictory results \\
\hline & Add-on & HIVPN & Effective (level III) \\
\hline Levetiracetam & Monotherapy & Various etiologies & Ineffective \\
\hline Maprotiline & Monotherapy & DPN & Effective (level III) \\
\hline
\end{tabular}


Table 1 continued

\begin{tabular}{|c|c|c|c|}
\hline Drug & Monotherapy or add-on & Type of polyneuropathy & Effectiveness $^{\mathrm{a}}$ \\
\hline Mexiletine & Monotherapy & HIVPN & Ineffective \\
\hline Nutmeg extract oil (topical application) & Add on & $\mathrm{DPN}$ & Ineffective \\
\hline Oxcarbazepine & Monotherapy & DPN & Ineffective \\
\hline Oxycodone & Add-on & DPN & Effective (level II) \\
\hline Perampanel & Add-on & DPN & Ineffective \\
\hline \multirow[t]{3}{*}{ Pregabalin } & Monotherapy & DPN & Effective (level II) \\
\hline & Monotherapy & Prediabetic SFN & Effective (level III) \\
\hline & Monotherapy or add-on & HIVPN & Ineffective \\
\hline Prosaptide & Monotherapy & HIVPN & Ineffective \\
\hline Sodium valproate & Monotherapy & DPN & Contradictory results \\
\hline St. John's wort (topical application) & Monotherapy & Various etiologies & Ineffective \\
\hline Tanezumab & Monotherapy & DPN & Effective (level III) \\
\hline Topiramate & Monotherapy & $\mathrm{DPN}$ & Contradictory results \\
\hline Tramadol & Monotherapy or add-on & Various etiologies & Effective (level II) \\
\hline Venlafaxine & Monotherapy & DPN & Effective (level II) \\
\hline ABT-639 & Monotherapy & DPN & Ineffective \\
\hline DA-9801 & Monotherapy & DPN & Ineffective \\
\hline PF-05089771 & Monotherapy & DPN & Ineffective \\
\hline TKA731 & Monotherapy & $\mathrm{DPN}$ & Ineffective \\
\hline
\end{tabular}

CIPN Chemotherapy-induced peripheral neuropathy (NP), DPN diabetic PN, HIVPN human immunodeficiency virusinduced PN, SFN small-fibre neuropathy

${ }^{a}$ Evidence grade was according to the classification proposed by the American Society of Interventional Pain Physicians (ASIPP), where applicable [20]

\section{Herbal Therapies}

St. John's wort as monotherapy for the management of PNP [96], DA-9801 as monotherapy for the management of DPN [97] and topical application of nutmeg extract oil as add-on treatment of pain due to DPN [98] have been found to have no analgesic effect. To the contrary, application of a topical formulation of Citrullus colocynthis appears to significantly improve pain in patients with DPN [99].

\section{Other Treatments}

Acetyl L-carnitine [100], prosaptide [101], mexiletine [102] and the non-peptide NK1-receptor antagonist $T K A-731$ [103] have been studied in small RCTs for their respective analgesic effect in PNP; no analgesic effect was found.

A summary of the effectiveness of each drug mentioned in this review for managing pain due to $\mathrm{PN}$ is provided in Table 1. 


\section{DISCUSSION}

Our systematic review underscores the plethora of different pharmacological interventions that are available for the management of PNP. The majority of the RCTs studied populations of patients suffering from DPN, followed in decreasing number by populations of patients with HIVPN and CIPN, respectively. The results from these studies allows for specific recommendations to be made based on the cause of PNP.

Using the ASIPP criteria, the currently best available evidence for the management of painful DPN is on amitriptyline, duloxetine, gabapentin, pregabalin and venlafaxine as monotherapies and oxycodone as add-on therapy (level II of evidence). Weaker evidence for the management of painful DPN exists for dextromethorphan/quinidine, isosorbide dinitrate spray amitriptyline, maprotiline, lacosamide and tanezumab monotherapies and botulinum toxin type A, capsaicin $8 \%$ patch, cebranopadol and lacosamide add-on therapies (level III of evidence).

With regards to HIVPN, the currently best available evidence exists for gabapentin as monotherapy and capsaicin $8 \%$ patch, delta-9tetrahydrocannabinol and lamotrigine as addon therapies (level III of evidence). Interestingly, there is evidence that neither pregabalin nor amitriptyline are effective for the management of pain due to HIVPN.

With regards to CIPN, the currently best available evidence is on duloxetine as an add-on therapy (level III of evidence).

These observations highlight the possibility that response to treatment may be affected by the underlying pathophysiological mechanisms that are involved in the pathogenesis of the PN. Consequently, it is very important to thoroughly examine patients presenting with PNP to determine the exact causes of the PN.

Our results should be interpreted with some caution given the limitations of our study design. Firstly, we only searched for publications in PubMed and clinicaltrials.gov; therefore, it is possible that some studies that were only indexed in other databases were missed.
Moreover, there was a great deal of heterogeneity in terms of the manner in which $\mathrm{PN}$ was diagnosed. In the majority of studies PN was diagnosed on the basis of symptoms and/or clinical examination, with only a few studies including an electrophysiological evaluation, which is important to determine the type and the severity of PN [104]

Future RCTs need to be conducted to shed more light on the use of pharmacological approaches in patients with other forms of PNP, but also to make a face-to-face comparison of the available effective treatments with the aim to design specific treatment algorithms.

\section{ACKNOWLEDGEMENTS}

Funding. No funding or sponsorship was received for this study or publication of this article.

Authorship. All named authors meet the International Committee of Medical Journal Editors (ICMJE) criteria for authorship for this article, take responsibility for the integrity of the work as a whole, and have given their approval for this version to be published.

Disclosures. Andreas Liampas, Martina Rekatsina and Athina Vadalouca have nothing to disclose. Antonella Paladini, Giustino Varrassi and Panagiotis Zis are members of the journal's Editorial Board.

Compliance with Ethics Guidelines. This article is based on previously conducted studies and does not contain any studies with human participants performed by any of the authors. Therefore, ethics review was not required.

Open Access. This article is licensed under a Creative Commons Attribution-NonCommercial 4.0 International License, which permits any non-commercial use, sharing, adaptation, distribution and reproduction in any medium or format, as long as you give appropriate credit to the original author(s) and the source, provide a link to the Creative Commons licence, and 
indicate if changes were made. The images or other third party material in this article are included in the article's Creative Commons licence, unless indicated otherwise in a credit line to the material. If material is not included in the article's Creative Commons licence and your intended use is not permitted by statutory regulation or exceeds the permitted use, you will need to obtain permission directly from the copyright holder. To view a copy of this licence, visit http://creativecommons.org/licenses/by$\mathrm{nc} / 4.0 /$.

\section{REFERENCES}

1. Zis P, Sarrigiannis PG, Rao DG, Hewamadduma C, Hadjivassiliou M. Chronic idiopathic axonal polyneuropathy: a systematic review. J Neurol. 2016;263(10):1903-10.

2. Gross JL, De Azevedo MJ, Silveiro SP, Canani LH, Caramori ML, Zelmanovitz T. Diabetic nephropathy: diagnosis, prevention, and treatment. Diabetes Care. 2005;28(1):164-76.

3. Zis P, Varrassi G. Painful peripheral neuropathy and cancer. Pain Ther. 2017;6(2):115-6.

4. Brozou V, Vadalouca A, Zis P. Pain in platin-induced neuropathies: a systematic review and meta-analysis. Pain Ther. 2018;7(1):105-19.

5. Zis P, Paladini A, Piroli A, McHugh PC, Varrassi G, Hadjivassiliou M. Pain as a first manifestation of paraneoplastic neuropathies: a systematic review and meta-analysis. Pain Ther. 2017;6(2):143-51.

6. Julian T, Glascow N, Syeed R, Zis P. Alcohol-related peripheral neuropathy: a systematic review and meta-analysis. J Neurol. 2019;266(12):2907-19.

7. Zis P, Rao DG, Sarrigiannis PG, et al. Transglutaminase6 antibodies in gluten neuropathy. Dig Liver Dis. 2017;49(11):1196-200.

8. Mallet ML, Hadjivassiliou M, Sarrigiannis PG, Zis P. The role of oxidative stress in peripheral neuropathy. J Mol Neurosci. 2020;70(7):1009-1017.

9. Zis P, McHugh PC, Manca M, Sarrigiannis PG, Rao DG, Hadjivassiliou M. Increased oxidative stress as a risk factor in chronic idiopathic axonal polyneuropathy. J Mol Neurosci. 2018;66(4):547-51.

10. Zis P, Sarrigiannis PG, Rao DG, Hadjivassiliou M. Gluten neuropathy: prevalence of neuropathic pain and the role of gluten-free diet. J Neurol. 2018a;265(10):2231-6.

11. Zis P, Sarrigiannis PG, Rao DG, Hewamadduma C, Hadjivassiliou M. Chronic idiopathic axonal polyneuropathy: prevalence of pain and impact on quality of life. Brain Behav. 2019;9(1):e01171.

12. Michaelides A, Hadden RDM, Sarrigiannis PG, Hadjivassiliou M, Zis P. Pain in chronic inflammatory demyelinating polyradiculoneuropathy: a systematic review and meta-analysis. Pain Ther. 2019;8(2):177-85.

13. Girach A, Julian TH, Varrassi G, Paladini A, Vadalouka A, Zis P. Quality of life in painful peripheral neuropathies: a systematic review. Pain Res Manag. 2019;2019:2091960.

14. Zis P, Sarrigiannis PG, Rao DG, Hadjivassiliou M. Quality of life in patients with gluten neuropathy: a case-controlled study. Nutrients. 2018;10(6):662.

15. Freynhagen R, Bennett MI. Diagnosis and management of neuropathic pain. BMJ. 2009;339:b3002.

16. Liampas A, Rekatsina M, Vadalouca A, Paladini A, Varrassi G, Zis P. Non-pharmacological management of painful peripheral neuropathies: a systematic review. Adv Ther. 2020;37:4096-106.

17. Jadad AR, Moore RA, Caroll D, et al. Assessing the quality of reports of randomized clinical trials: is blinding necessary? Control Clin Trials. 1996;17(1): $1-12$.

18. Higgins JP, Altman DG, Gøtzsche PC, et al. The Cochrane Collaboration's tool for assessing risk of bias in randomised trials. BMJ. 2011;18(343):d5928.

19. Moher D, Liberati A, Tetzlaff J, Altman DG, PRISMA Group. Preferred reporting items for systematic reviews and meta-analyses: the PRISMA statement. PLoS Med. 2009;6(7):e1000097.

20. Manchikanti L, Falco FJ, Benyamin RM, Kaye AD, Boswell MV, Hirsch JA. A modified approach to grading of evidence. Pain Phys. 2014;17(3): E319-25.

21. Backonja M, Beydoun A, Edwards KR, et al. Gabapentin for the symptomatic treatment of painful neuropathy in patients with diabetes mellitus: a randomized controlled trial. JAMA. 1998;280(21): 1831-6.

22. Hahn K, Arendt G, Braun JS, et al. A placebo-controlled trial of gabapentin for Painful HIV-associated sensory neuropathies. J Neurol. 2004;251(10): 1260-6. 
23. Rao RD, Michalak JC, Sloan JA, et al. Efficacy of gabapentin in the management of chemotherapyinduced peripheral neuropathy: a phase 3 randomized, double-blind, placebo-controlled, crossover trial (NO0C3). Cancer. 2007;110(9):2110-8.

24. Rauck R, Makumi CW, Schwartz S, et al. A randomized, controlled trial of gabapentin enacarbil in subjects with neuropathic pain associated with diabetic peripheral neuropathy. Pain Pract. 2013;13(6):485-96.

25. Morello CM, Leckband SG, Stoner CP, Moorhouse DF, Sahagian GA. Randomized double-blind study comparing the efficacy of gabapentin with amitriptyline on diabetic peripheral neuropathy pain. Arch Intern Med. 1999;159(16):1931-7.

26. Gilron I, Bailey JM, Tu D, Holden RR, Jackson AC, Houlden RL. Nortriptyline and gabapentin, alone and in combination for neuropathic pain: a doubleblind, randomised controlled crossover trial. Lancet. 2009;374(9697):1252-61.

27. Sandercock D, Cramer M, Biton V, Cowles VE. A gastroretentive gabapentin formulation for the treatment of painful diabetic peripheral neuropathy: efficacy and tolerability in a double-blind, randomized, controlled clinical trial. Diabetes Res Clin Pract. 2012;97(3):438-45.

28. Lesser H, Sharma U, LaMoreaux L, Poole RM. Pregabalin relieves symptoms of painful diabetic neuropathy: a randomized controlled trial. Neurology. 2004;63(11):2104-10.

29. Rosenstock J, Tuchman M, LaMoreaux L, Sharma U. Pregabalin for the treatment of painful diabetic peripheral neuropathy: a double-blind, placebocontrolled trial. Pain. 2004;110(3):628-38.

30. Richter RW, Portenoy R, Sharma U, Lamoreaux L, Bockbrader H, Knapp LE. Relief of painful diabetic peripheral neuropathy with pregabalin: a randomized, placebo-controlled trial. J Pain. 2005;6(4): 253-60.

31. Arezzo JC, Rosenstock J, LaMoreaux L, Pauer L. Efficacy and safety of pregabalin $600 \mathrm{mg} / \mathrm{d}$ for treating painful diabetic peripheral neuropathy: a double-blind placebo-controlled trial. BMC Neurol. 2008;8:33.

32. Satoh J, Yagihashi S, Baba M, et al. Efficacy and safety of pregabalin for treating neuropathic pain associated with diabetic peripheral neuropathy: a 14 week, randomized, double-blind, placebo-controlled trial. Diabet Med. 2011;28(1):109-16.

33. Huffman C, Stacey BR, Tuchman M, et al. Efficacy and safety of pregabalin in the treatment of patients with painful diabetic peripheral neuropathy and pain on walking. Clin J Pain. 2015;31(11):946-58.

34. Raskin P, Huffman C, Yurkewicz L, et al. Pregabalin in patients with painful diabetic peripheral neuropathy using an NSAID for other pain conditions: a double-blind crossover study. Clin J Pain. 2016;32(3):203-10.

35. Mu Y, Liu X, Li Q, et al. Efficacy and safety of pregabalin for painful diabetic peripheral neuropathy in a population of chinese patients: a randomized placebo-controlled trial. J Diabetes. 2018;10(3): 256-65.

36. Bansal D, Bhansali A, Hota D, Chakrabarti A, Dutta P. Amitriptyline vs. pregabalin in painful diabetic neuropathy: a randomized double blind clinical trial. Diabet Med. 2009;26(10):1019-26.

37. Holbech JV, Bach FW, Finnerup NB, Brøsen K, Jensen S, Sindrup SH. Imipramine and pregabalin combination for painful polyneuropathy: a randomized controlled trial. Pain. 2015;156(5):958-66.

38. Tesfaye S, Wilhelm S, Lledo A, et al. Duloxetine and pregabalin: high-dose monotherapy or their combination? The "COMBO-DN Study"-a multinational, randomized, double-blind, parallel-group study in patients with diabetic peripheral neuropathic pain. Pain. 2013;154(12):2616-25.

39. González-Duarte A, Lem M, Díaz-Díaz E, Castillo C, Cárdenas-Soto K. The efficacy of pregabalin in the treatment of prediabetic neuropathic pain. Clin J Pain. 2016;32(11):927-32.

40. Simpson DM, Rice ASC, Emir B, et al. A randomized, double-blind, placebo-controlled trial and open-label extension study to evaluate the efficacy and safety of pregabalin in the treatment of neuropathic pain associated with human immunodeficiency virus neuropathy. Pain. 2014;155(10):1943-54.

41. Simpson DM, Schifitto G, Clifford DB, et al. Pregabalin for painful HIV neuropathy: a randomized, double-blind, placebo-controlled trial. Neurology. 2010;74(5):413-20.

42. Raskin P, Donofrio PD, Rosenthal NR, et al. Topiramate vs placebo in painful diabetic neuropathy: analgesic and metabolic effects. Neurology. 2004;63(5):865-73.

43. Thienel U, Neto W, Schwabe SK, Vijapurkar U, Topiramate Diabetic Neuropathic Pain Study Group. Topiramate in painful diabetic polyneuropathy: findings from three double-blind placebocontrolled trials. Acta Neurol Scand. 2004;110(4): 221-31. 
44. Rauck RL, Shaibani A, Biton V, Simpson J, Koch B. Lacosamide in painful diabetic peripheral neuropathy: a phase 2 double-blind placebo-controlled study. Clin J Pain. 2007;23(2):150-8.

45. Ziegler D, Hidvégi T, Gurieva I, et al. Efficacy and safety of lacosamide in painful diabetic neuropathy. Diabetes Care. 2010;33(4):839-41.

46. Wymer JP, Simpson J, Sen D, Bongardt S, Lacosamide SP742 Study Group. Efficacy and safety of lacosamide in diabetic neuropathic pain: an 18-week double-blind placebo-controlled trial of fixed-dose regimens. Clin J Pain. 2009;25(5): 376-85.

47. de Greef BTA, Hoeijmakers JGJ, Geerts M, et al. Lacosamide in patients with Nav1.7 mutations-related small fibre neuropathy: a randomized controlled trial. Brain. 2019;142(2):263-75.

48. Eisenberg E, Lurie Y, Braker C, Daoud D, Ishay A. Lamotrigine reduces painful diabetic neuropathy: a randomized, controlled study. Neurology. 2001;57(3):505-9.

49. Jose VM, Bhansali A, Hota D, Pandhi P. Randomized double-blind study comparing the efficacy and safety of lamotrigine and amitriptyline in painful diabetic neuropathy. Diabet Med. 2007;24(4): 377-83.

50. Vinik AI, Tuchman M, Safirstein B, et al. Lamotrigine for treatment of pain associated with diabetic neuropathy: results of two randomized, doubleblind, placebo-controlled studies. Pain. 2007;128(1-2):169-79.

51. Rao RD, Flynn PJ, Sloan JA, et al. Efficacy of lamotrigine in the management of chemotherapy-induced peripheral neuropathy: a phase 3 randomized, double-blind, placebo-controlled trial, N01C3. Cancer. 2008;112(12):2802-8.

52. Simpson DM, Olney R, McArthur JC, Khan A, Godbold J, Ebel-Frommer K. A placebo-controlled trial of lamotrigine for painful HIV-associated neuropathy. Neurology. 2000;54(11):2115-9.

53. Kochar DK, Jain N, Agrawal RP, Srivastava T, Agrawal P, Gupta S. Sodium valproate in the management of painful neuropathy in type 2 diabetes - a randomized placebo controlled study. Acta Neurol Scand. 2002;106(5):248-52.

54. Agrawal RP, Goswami J, Jain S, Kochar DK. Management of diabetic neuropathy by sodium valproate and glyceryl trinitrate spray: a prospective double-blind randomized placebo-controlled study. Diabetes Res Clin Pract. 2009;83(3):371-8.
55. Otto M, Bach FW, Jensen TS, Sindrup SH. Valproic acid has no effect on pain in polyneuropathy: a randomized, controlled trial. Neurology. 2004;62(2):285-8.

56. Beydoun A, Shaibani A, Hopwood M, Wan Y. Oxcarbazepine in painful diabetic neuropathy: results of a dose-ranging study. Acta Neurol Scand. 2006;113(6):395-404.

57. Holbech JV, Otto M, Bach FW, Jensen TS, Sindrup $\mathrm{SH}$. The anticonvulsant levetiracetam for the treatment of pain in polyneuropathy: a randomized, placebo-controlled, cross-over trial. Eur J Pain. 2011;15(6):608-14.

58. ClinicalTrials.gov.Bethesda (MD): National Library of Medicine (US). 29 Feb 2000. Identifier NCT00505284, an evaluation of the efficacy and safety of E2007 in patients with painful diabetic neuropathy; Jully 2008 [about 4 screens]. https:// clinicaltrials.gov/ct2/show/study/NCT00505284. Accessed 24 July 2020.

59. Ziegler D, Duan WR, An G, Thomas JW, Nothaft W. A randomized double-blind, placebo-, and activecontrolled study of T-type calcium channel blocker ABT-639 in patients with diabetic peripheral neuropathic pain. Pain. 2015;156(10):2013-20.

60. McDonnell A, Collins S, Ali Z, et al. Efficacy of the Nav1.7 blocker PF-05089771 in a randomised, placebo-controlled, double-blind clinical study in subjects with painful diabetic peripheral neuropathy. Pain. 2018;159(8):1465-76.

61. Rowbotham MC, Veeraindar G, Kunz NR, Lei D. Venlafaxine extended release in the treatment of painful diabetic neuropathy: a double-blind, placebo-controlled study. Pain. 2004;110(3):697-706.

62. Hai-yan J, Qifu L, Dian-ping S, et al. Effects of venlafaxine and carbamazepine for painful peripheral diabetic neuropathy: a randomized, doubleblind and double- dummy, controlled multi-center trial. Chin J Evid Based Med. 2006;6:74414617.

63. Sindrup SH, Bach FW, Madsen C, Gram LF, Jensen TS. Venlafaxine versus imipramine in painful polyneuropathy: a randomized, controlled trial. Neurology. 2003;60(8):1284-9.

64. Razazian N, Baziyar M, Moradian N, Afshari D, Bostani A, Mahmoodi M. Evaluation of the efficacy and safety of pregabalin, venlafaxine, and carbamazepine in patients with painful diabetic peripheral neuropathy. A randomized, double-blind trial. Neurosciences. 2014;19(3):192-8.

65. Raskin J, Pritchett YL, Wang F, et al. A double-blind, randomized multicenter trial comparing duloxetine with placebo in the management of diabetic 
peripheral neuropathic pain. Pain Med. 2005;6(5): 346-56.

66. Goldstein DJ, Lu Y, Detke MJ, Lee TC, Iyengar S. Duloxetine vs. placebo in patients with painful diabetic neuropathy. Pain. 2005;116(1-2):109-18.

67. ClinicalTrials.gov. Bethesda (MD): National Library of Medicine (US). 29 Feb 2000. Identifier NCT00552175, a study for the treatment of diabetic peripheral neuropathic pain; 2009 March; [about 4 screens]. https://clinicaltrials.gov/ct2/show/ NCT00552175. Accessed 24 July 2020.

68. Smith EML, Pang H, Cirrincione C, et al. Effect of duloxetine on pain, function, and quality of life among patients with chemotherapy-induced painful peripheral neuropathy: a randomized clinical trial. JAMA. 2013;309(13):1359-67.

69. Majdinasab N, Kaveyani H, Azizi M. A comparative double-blind randomized study on the effectiveness of duloxetine and gabapentin on painful diabetic peripheral polyneuropathy. Drug Des Dev Ther. 2019;13:1985-92.

70. ClinicalTrials.gov. Bethesda (MD): National Library of Medicine (US). 29 Feb 2000. Identifier NCT02417935, a study of duloxetine (LY248686) in participants with diabetic peripheral neuropathic pain (DPNP); 2017 May 13; [about 4 screens]. https://clinicaltrials.gov/ct2/show/NCT02417935. Accessed 24 July 2020.

71. Vrethem M, Boivie J, Arnqvist $H$, Holmgren $H$, Lindström T, Thorell LH. A comparison a amitriptyline and maprotiline in the treatment of painful polyneuropathy in diabetics and nondiabetics. Clin J Pain. 1997;13(4):313-23.

72. Kieburtz K, Simpson D, Yiannoutsos C, et al. A randomized trial of amitriptyline and mexiletine for painful neuropathy in HIV infection. AIDS clinical trial group 242 protocol team. Neurology. 1998;51(6):1682-8.

73. Dinat N, Marinda E, Moch S, Rice ASC, Kamerman PR. Randomized, double-blind, crossover trial of amitriptyline for analgesia in painful HIV-associated sensory neuropathy. PLoS ONE. 2015;10(5): e0126297.

74. Otto M, Bach FW, Jensen TS, Brøsen K, Sindrup SH. Escitalopram in painful polyneuropathy: a randomized, placebo-controlled, cross-over trial. Pain. 2008;139(2):275-83.

75. Harati Y, Gooch C, Swenson M, et al. Double-blind randomized trial of tramadol for the treatment of the pain of diabetic neuropathy. Neurology. 1998;50(6):1842-6.
76. Sindrup SH, Andersen G, Madsen C, Smith T, Brøsen $\mathrm{K}$, Jensen TS. Tramadol relieves pain and allodynia in polyneuropathy: a randomised, doubleblind, controlled trial. Pain. 1999;83(1):85-90.

77. Freeman R, Raskin P, Hewitt DJ, et al.. Randomized study of tramadol/acetaminophen versus placebo in painful diabetic peripheral neuropathy. Curr Med Res Opin. 2007;23(1):147-61.

78. Watson CPN, Moulin D, Watt-Watson J, Gordon A, Eisenhoffer J. Controlled-release oxycodone relieves neuropathic pain: a randomized controlled trial in painful diabetic neuropathy. Pain. 2003;105(1-2): 71-8.

79. Gimbel JS, Richards P, Portenoy RK. Controlled-release oxycodone for pain in diabetic neuropathy: a randomized controlled trial. Neurology. 2003;60(6): 927-34.

80. ClinicalTrials.gov [Internet]. Bethesda (MD): National Library of Medicine (US). 2000 Feb 29. Identifier NCT00944697, a study to demonstrate the analgesic efficacy of oxycodone/naloxone prolonged release tablets in addition to pregabalin compared to pregabalin alone in opioid-naïve subjects treated with pregabalin suffering from moderate to severe pain due to diabetic polyneuropathy; April 2010; [about 4 screens]. https://clinicaltrials. gov/ct2/show/study/NCT00944697. Accessed 24 July 2020.

81. Shaibani AI, Pope LE, Thisted R, Hepner A. Efficacy and safety of dextromethorphan/quinidine at two dosage levels for diabetic neuropathic pain: a double-blind, placebo-controlled, multicenter study. Pain Med. 2012;13(2):243-54.

82. ClinicalTrials.gov [Internet]. Bethesda (MD): National Library of Medicine (US). 29 Feb 2000. Identifier NCT01939366, cebranopadol efficacy and safety in diabetic patients suffering from chronic pain caused by damage to the nerves; 2015 January; [about 4 screens]. https://clinicaltrials.gov/ct2/ show/NCT01939366. Accessed 28 Aug 2020.

83. Abrams DI, Jay CA, Shade SB, et al. Cannabis in painful HIV-associated sensory neuropathy: a randomized placebo-controlled trial. Neurology. 2007;68(7):515-21.

84. Ellis RJ, Toperoff W, Vaida F, et al. Smoked medicinal cannabis for neuropathic pain in HIV: a randomized, crossover clinical trial. Neuropsychopharmacology. 2009;34(3):672-80.

85. Clifford DB, Simpson DM, Brown S, et al. A randomized, double-blind, controlled study of NGX4010 , a capsaicin 8\% dermal patch, for the treatment of painful HIV-associated distal sensory 
polyneuropathy. J Acquir Immune Defic Syndr. 2012;59(2):126-33.

86. Simpson DM, Robinson-Papp J, Van J, et al. Capsaicin $8 \%$ patch in painful diabetic peripheral neuropathy: a randomized, double-blind, placebocontrolled study. J Pain. 2017;18(1):42-53.

87. Kulkantrakorn K, Lorsuwansiri C, Meesawatsom P. $0.025 \%$ Capsaicin gel for the treatment of painful diabetic neuropathy: a randomized, double-blind, crossover, placebo-controlled trial. Pain Pract. 2013;13(6):497-503.

88. Kulkantrakorn K, Chomjit A, Sithinamsuwan P, Tharavanij T, Suwankanoknark J, Napunnaphat P. $0.075 \%$ Capsaicin lotion for the treatment of painful diabetic neuropathy: a randomized, doubleblind, crossover, placebo-controlled trial. J Clin Neurosci. 2019;62:174-9.

89. ClinicalTrials.gov. Bethesda (MD): National Library of Medicine (US). 29 Feb 2000. Identifier NCT00476151, a study of the efficacy and safety of amitriptyline/ketamine topical cream in patients with diabetic peripheral neuropathy; 2008 Apr; [about 4 screens]. https://clinicaltrials.gov/ct2/ show/study/NCT00476151. Accessed 24 July 2020.

90. Gewandter JS, Mohile SG, Heckler CE, et al. A phase III randomized, placebo-controlled study of topical amitriptyline and ketamine for chemotherapy-induced peripheral neuropathy (CIPN): a University of Rochester CCOP study of 462 cancer survivors. Support Care Cancer. 2014;22(7):1807-14.

91. Agrawal RP, Choudhary R, Sharma P, et al. Glyceryl trinitrate spray in the management of painful diabetic neuropathy: a randomized double blind placebo controlled cross-over study. Diabetes Res Clin Pract. 2007;77(2):161-7.

92. Yuen KCJ, Baker NR, Rayman G. Treatment of chronic painful diabetic neuropathy with isosorbide dinitrate spray: a double-blind placebo-controlled cross-over study. Diabetes Care. 2002;25(10): 1699-703.

93. Cambell CM, Kipnes MS, Stouch BC, et al. Randomized control trial of topical clonidine for treatment of painful diabetic neuropathy. Pain. 2012;153(9):1815-23.

94. Bramson C, Herrmann DN, Carey W, et al. Exploring the role of tanezumab as a novel treatment for the relief of neuropathic pain. Pain Med. 2015;16(6):1163-76.
95. Yuan RY, Sheu JJ, Yu JM, et al. Botulinum toxin for diabetic neuropathic pain: a randomized doubleblind crossover trial. Neurology. 2009;72(17): 1473-8.

96. Sindrup SH, Madsen C, Bach FW, Gram LF, Jensen TS. St. John's wort has no effect on pain in polyneuropathy. Pain. 2001;91(3):361-5.

97. ClinicalTrials.gov. Bethesda (MD): National Library of Medicine (US). 29 Feb 2000. Identifier NCT01822925, a phase II randomized, doubleblind, parallel group, dose-ranging, placebo-controlled study to assess the safety and effectiveness of DA-9801 in the treatment of subjects with diabetic neuropathy; 2015 January; [about 4 screens]. https://clinicaltrials.gov/ct2/show/NCT01822925. Accessed 28 Aug 2020.

98. Motilal S, Maharaj RG. Nutmeg extracts for painful diabetic neuropathy: a randomized, double-blind, controlled study. J Altern Complement Med. 2013;19(4):347-52.

99. Heydari M, Homayouni K, Hashempur MH, Shams M. Topical Citrullus colocynthis (bitter apple) extract oil in painful diabetic neuropathy: a double-blind randomized placebo-controlled clinical trial. J Diabetes. $2016 ; 8(2): 246-52$.

100. Youle M, Osio M, ALCAR Study Group. A doubleblind, parallel-group, placebo-controlled, multicentre study of acetyl L-carnitine in the symptomatic treatment of antiretroviral toxic neuropathy in patients with HIV-1 infection. HIV Med. 2007;8(4):241-50.

101. Evans SR, Simpson DM, Kitch DW, et al. A randomized trial evaluating Prosaptide ${ }^{\mathrm{TM}}$ for HIV-associated sensory neuropathies: use of an electronic diary to record neuropathic pain. PLoS ONE. 2007;2(7):e551.

102. Wright JM, Oki JC, Graves L 3rd. Mexiletine in the symptomatic treatment of diabetic peripheral neuropathy. Ann Pharmacother. 1997;31(1):29-34.

103. Sindrup SH, Graf A, Sfikas N. The NK1-receptor antagonist TKA731 in painful diabetic neuropathy: a randomised, controlled trial. Eur J Pain. 2006;10(6):567-71.

104. Zis P, Hadjivassiliou M, Rao DG, Sarrigiannis PG. Electrophysiological determinants of the clinical severity of axonal peripheral neuropathy. Muscle Nerve. 2019;59(4):491-3. 